\title{
Human Monocyte Antibody-Dependent Cell-Mediated Cytotoxicity to Tumor Cells
}

\author{
George M. Shaw, Paul C. Levy, and Albert F. LoBuglio, Division of Hematology \\ and Oncology, Department of Medicine, Ohio State University, \\ Columbus, Ohio 43210
}

\begin{abstract}
A B S T R A C T Previous investigations of mononuclear cell antibody-dependent cell-mediated cytotoxicity (ADCC) toward tumor cells suggest that K lymphocytes and not monocytes are active in this cytotoxic reaction. This report, however, demonstrates that human monocytes are able to carry out ADCC toward three different human tumor cell lines (CEM T lymphoblasts, Raji bone marrow-derived (B) lymphoblasts, and HeLa cells). The cytolytic event was found to be temperature dependent and rapid, with most of the lysis occurring in the first $4 \mathrm{~h}$ of incubation. The extent of lysis was directly related to the number of monocytes (effector cells) and to the degree of antibody sensitization of the target cells. The antibody-dependent cell contact-mediated nature of the cytolytic event was confirmed by inhibition with competing nonspecific monomeric immunoglobulin and by the ability of monocytes in "innocent bystander" experiments to lyse antibody-coated targets but not nonantibody-coated target cells. Evidence that monocytes were clearly the effector cells in the monocyte preparations included the observation that preincubation of effector cells with opsonized zymosan particles abolished ADCC by monocytes, but had little effect on lymphocyte ADCC. Furthermore, no evidence for $F_{c}$ receptor $K$ lymphocyte contamination of the monocyte preparations was found using antibody-coated target cells that were selectively lysed by lymphocytes but not monocytes. We suggest that ADCC toward tumor cell targets may prove to be a useful assay of monocyte function in normal and disease states.
\end{abstract}

\section{INTRODUCTION}

Destruction of erythroid, lymphoid, and tumor cell targets by human leukocytes is currently a subject of ac-

Dr. Shaw was supported by the Roessler Foundation and a fellowship from the Pharmaceutical Manufacturers Association.

Received for publication 16 June 1978 and in revised form 18 August 1978. tive immunologic interest and investigation. One means by which leukocytes lyse these target cells is termed antibody-dependent cell-mediated cytotoxicity (ADCC). ${ }^{1}$ In this process, $F_{c}$ receptor bearing nonimmune leukocytes bind and destroy immunoglobulin ( $\mathrm{Ig}) \mathrm{G}$ antibody-coated target cells. Monocytes, neutrophils, and $\mathrm{K}$ lymphocytes all possess $\mathrm{Fc}_{\mathrm{c}}$ receptors, and have been shown in vitro to carry out ADCC toward certain cell targets (1-3). In vivo studies suggest that these ADCC reactions may be operative in graft (4) and tumor (5-8) rejection, in resistance to viral infection (9), and in certain autoimmune reactions (10).

Examination of ADCC toward tumor cell targets in particular continues to be a primary focus of investigation. Previous reports indicate that $\mathrm{K}$ lymphocytes and neutrophils are active in this cytolytic process whereas monocytes are reported to be incapable of antibodymediated tumor cell destruction (1-3, 11-18). In previous studies, we demonstrated that human monocytes possess $\mathrm{Fc}_{\mathrm{c}}$ receptors capable of binding IgGcoated human erythrocytes (19), and there is evidence that attached erythrocytes undergo spherocytosis and lysis (20-21). These findings, along with the report by Kohl et al. (9) that monocyte-macrophages can produce modest destruction of herpes infected Chang cells coated with antiviral antibody, led us to investigate further the capacity of normal human monocytes to carry out ADCC to tumor cells. In this study, we describe monocyte ADCC toward three human tumor cell lines and examine the basic characteristics of monocyte ADCC.

\section{METHODS}

Effector cells. To obtain preparations of monocytes, blood was collected in $\mathrm{Na}_{2} \mathrm{H}_{2}$ EDTA ( $15 \mathrm{mg} / 10 \mathrm{~cm}^{3}$ blood) and subjected to Ficoll-Hypaque density centrifugation (23). The mononuclear cells were harvested, washed, and resuspended

\footnotetext{
${ }^{1}$ Abbreviations used in this paper: ADCC, antibody-dependent cell-mediated cytotoxicity; E:T ratio, effector:target ratio; SPA, staphylococcal protein A.
} 
in Seligmann's balanced salt solution at a concentration of $30 \times 10^{6} / \mathrm{cm}^{3}$. Monocyte monolayers were prepared as described (24). $50 \mu \mathrm{l}$ aliquots of the cell suspension were added to Falcon 3040 microtest wells (Falcon Plastics, Div. of BioQuest, Oxnard, Calif.) containing $150 \mu \mathrm{l}$ Hanks' balanced salt solution supplemented with $13 \%$ heat inactivated human $\mathrm{AB}$ serum. After incubating $90 \mathrm{~min}$ at $37^{\circ} \mathrm{C}$ in a humidified $95 \%$ air, $5 \% \mathrm{CO}_{2}$ atmosphere, the monolayers were washed vigorously five times with complete RPMI medium supplemented with $10 \%$ heat-inactivated fetal calf serum, $0.3 \mathrm{mg} / \mathrm{ml} \mathrm{L-glutamine,} 0.1 \mathrm{mg} / \mathrm{ml}$ gentamicin, and $100 \mathrm{U} / \mathrm{ml}$ penicillin). The number of adherent cells in the monolayers was determined by lysing cells in three wells with Zap-Isoton II (Coulter Diagnostics Inc., Hialeah, Fla.) and counting the nuclei in a Coulter counter. The mean number of cells in the three wells was used as the effector cell number in the assay. Individual wells varied by $<10 \%$ from the mean. Purity of the monocytes in the monolayers was $>95 \%$ as determined by latex ingestion, nonspecific esterase staining, and morphology of adherent monolayer cells, or cells harvested from the monolayers (see below).

For certain experiments, "suspension" monocytes were employed. Monocyte monolayers were prepared in $100 \mathrm{~mm}$ diameter tissue culture plates (Falcon Plastics) and then treated with an ice-cold solution of $0.2 \%$ EDTA plus $0.1 \%$ bovine serum albumin in normal saline for $1 \mathrm{~min}$ and gently removed with a rubber policeman. These monocyte suspensions were $>95 \%$ pure and $>90 \%$ viable by trypan blue criteria.

Lymphocyte suspensions depleted of monocytes were prepared by carbonyl iron separation (23). In brief, carbonyl iron powder $(300 \mathrm{mg})$ in $2.5 \mathrm{~cm}^{3} 5 \%$ dextran-buffered salt solution was added to each $10 \mathrm{~cm}^{3}$ of heparinized blood (10 $\mathrm{U} / \mathrm{ml}$ ) and incubated at $37^{\circ} \mathrm{C}$ for $45 \mathrm{~min}$ on an end-over-end rotating wheel. The blood was then separated on a FicollHypaque gradient and the nonphagocytic mononuclear cells removed from the upper layer, washed twice, and resuspended in complete RPMI medium. This preparative technique has been shown to retain $F_{c}$ receptor-positive $K$ lymphocytes that are nonphagocytic and nonsurface adherent (25). This monoculear cell preparation routinely contained $>95 \%$ lymphocytes as determined by morphology, nonspecific esterase staining, and inability to phagocytize latex particles. $10-20 \%$ of these cells were $F_{c}$ receptor-positive as determined by rosette formation with Ripley antibody-coated human erythrocytes (26).

Target cells. Three different human tumor cell lines were employed for targets in this study. These included thymusderived (T) lymphoblasts (CEM), bone marrow-derived (B) lymphoblasts (Raji), and cervical carcinoma cells (HeLa). The CEM lymphoblast target cell was used for most studies to characterize monocyte cytotoxic activity. This T-cell line was derived from a childhood leukemic patient (27) and lacks demonstrable Epstein-Barr virus genome (28), possesses the HLA antigen phenotype Al, A10, B8, Bw40 (29), and is incapable of stimulating a mixed leukocyte culture response (29). All cell lines were grown in complete RPMI medium and were subcultured every 4 days. CEM and Raji cells grew in suspension, whereas HeLa cells were surface adherent. Before use, this latter cell line was removed from the monolayer with $0.25 \%$ trypsin (Grand Island Biological Co., Grand Island, N. Y.) in Hanks' balanced salt solution without $\mathrm{Ca}^{++}$ or $\mathbf{M g}^{++}$

Radioactive labeling of target cells was done by incubating $20 \times 10^{6}$ cells in $0.3 \mathrm{~cm}^{3}$ Tris buffer solution (30) containing $150 \mu \mathrm{Ci}{ }^{51} \mathrm{Cr}$ (sodium chromate, New England Nuclear, Boston, Mass.) for $90 \mathrm{~min}$ at $37^{\circ} \mathrm{C}$ with gentle agitation every $15 \mathrm{~min}$. They were then washed once with complete
RPMI and antibody coated by incubating $10 \times 10^{6}$ cells with $0.2 \mathrm{~cm}^{3}$ of undiluted serum (unless stated otherwise) for 45 min at $37^{\circ} \mathrm{C}$. Control nonantibody-coated targets were carried through an identical incubation without antiserum or in the presence of nonimmune rabbit serum. The cells were then washed five times in complete RPMI and resuspended at the desired concentration.

Serum. A New Zealand White rabbit was immunized on days $1,14,21$, and 28 with CEM lymphoblasts by intraperitoneal injections of $150 \times 10^{6}$ cells suspended in $10 \mathrm{~cm}^{3}$ of Hanks' balanced salt solution. The immune rabbit was bled by cardiac puncture on a weekly basis beginning on day 28 . Control nonimmune sera was obtained from an untreated rabbit. Blood was allowed to clot at $4^{\circ} \mathrm{C}$ overnight and then centrifuged. The sera was collected, heat inactivated at $56^{\circ} \mathrm{C}$ for 35 min, and stored at $-70^{\circ} \mathrm{C}$. All experiments described in this paper used serum from the first phlebotomy, although subsequent serum samples were similarly active in ADCC.

Microcytotoxicity assay. The monocyte ADCC assay was carried out in complete RPMI medium by incubating antibody- and nonantibody-coated target cells with monocyte monolayers. The effector to target ratio was 10:1 unless otherwise specified. Identical numbers of these same target cells were added to microwells without effector cells to determine spontaneous release of ${ }^{51} \mathrm{Cr}$. Assays were performed at $37^{\circ} \mathrm{C}$ in triplicate, and the final volume of each reaction mixture was $300 \mu \mathrm{l}$. The microtest plates were centrifuged at $50 \mathrm{~g}$ for $3 \mathrm{~min}$ to initiate cell contact and then incubated at $37^{\circ} \mathrm{C}$ in a humidified atmosphere of $95 \%$ air, $5 \% \mathrm{CO}_{2}$. After $4 \mathrm{~h}$ incubation, $100 \mu \mathrm{l}$ of supernate were removed from each well to determine the amount of ${ }^{51} \mathrm{Cr}$ released.

Target cell lysis, expressed as percentage of ${ }^{51} \mathrm{Cr}$ release, was calculated simply by dividing the total counts per minute released into the supernate by the total counts per minute added to each well. In this manner, the percentage of ${ }^{51} \mathrm{Cr}$ release from antibody- and nonantibody-coated target cells both in the presence and absence of effector cells could be determined. Standard deviations were calculated from the triplicate determinations of the percentage of ${ }^{51} \mathrm{Cr}$ release, assuming that the total counts per minute added to each well were constant between samples. To calculate ${ }^{51} \mathrm{Cr}$ release due specifically to antibody-dependent cytotoxicity, the following formula was used: percentage of $\mathrm{ADCC}=(\mathrm{A}-\mathrm{B}) / \mathrm{C} \times 100$. (A) mean counts per minute in supernate of wells containing antibody-coated target cells plus monocytes. (B) mean counts per minute in supernate of wells containing nonantibody-coated target cells plus monocytes. (C) mean total counts per minute of targets added to each well. Percentage of ${ }^{51} \mathrm{Cr}$ release from nonantibody-coated tumor cell targets was always the same as that from targets pretreated with nonimmune (control) rabbit serum, both in the presence and absence of effector cells.

Lymphocyte ADCC assays were carried out in an identical fashion except that lymphocytes and target cells were added to microwells as suspensions of cells and were immediately centrifuged together.

Experiments to characterize the ADCC assay. Experiments were performed to examine the basic characteristics of monocyte ADCC, including the time-course of target cell lysis and the effects of temperature, immune serum dilution, and effector:target ratio. To determine the effect of immunoglobulin on monocyte ADCC, a monomeric preparation of Cohn fraction II human gamma globulin (Travenol Laboratories, Inc. Morton Grove, Ill.) was prepared according to Ziegler and Henney (31). The stock gamma globulin solution was adjusted to $30 \mathrm{mg} / \mathrm{ml}$ in complete RPMI and ultracentrifuged for $1 \mathrm{~h}$ at $145,000 \mathrm{~g}$ immediately before use to remove spontaneously formed aggregates. Appropriate dilutions of this preparation were made, added to effector cell preparations, 
and preincubated at $37^{\circ} \mathrm{C}$ for $30 \mathrm{~min}$. The target cells were then added, and the assay carried out as previously described. To examine the need for intimate cell contact mediated through the $\mathrm{F}_{\mathrm{C}}$ receptor during monocyte ADCC, two studies were carried out. First, antibody-coated target cells were incubated with or without staphylococcal protein A (SPA) to determine the effect of SPA blocking of the Fc region of surface-bound antibody on subsequent monocyte ADCC as described by Rosenblatt et al. (32). Second, an innocent bystander study was designed. 100,000 monocytes were incubated with a mixture of equal numbers $\left(10^{4}\right)$ of antibodyand nonantibody-coated target cells. In one set of wells, only the antibody-coated targets carried the ${ }^{51} \mathrm{Cr}$ label, and in a second set of wells, only the nonantibody-coated targets carried the ${ }^{51} \mathrm{Cr}$ label. In this way, lysis of nonantibodycoated target cells (innocent bystanders) could be evaluated in microwells where monocytes were carrying out ADCC to the antibody-coated cells.

Experiments to delineate the effector cell responsible for tumor cell destruction. To establish that monocytes and not $\mathrm{Fc}_{\mathrm{c}}$ receptor lymphocytes were the cells in the monolayers responsible for ADCC, two functional studies were employed. The first involved preincubation of effector cell preparations (monocyte monolayers and lymphocytes obtained from the same donor) with zymosan particles (Sigma Chemical Co., St. Louis, Mo.) opsonized by nonspecific activation of the alternate complement pathway (33). Monocytes possess complement receptors and avidly ingest these particles (34), whereas $\mathrm{K}$ lymphocytes lack these receptors and are nonphagocytic (35). Thus, it seemed likely that monocyte ADCC could be selectively inhibited. In these experiments, 0.5 $\mathrm{cm}^{3}$ of a zymosan particle suspension $(50 \mathrm{mg} / \mathrm{ml}$ in normal saline) was incubated at $37^{\circ}$ with $1.5 \mathrm{~cm}^{3}$ of fresh $\mathrm{AB}$ serum. After $30 \mathrm{~min}$, the particles were washed twice and the pellet resuspended in $100 \mathrm{~cm}^{3}$ of complete RPMI. $100 \mu \mathrm{l}$ of this opsonized particle suspension were preincubated with the effector cells for $1 \mathrm{~h}$ at $37^{\circ} \mathrm{C}$, the target cells then added, and the assay completed as previously described.

A second technique was used to search for contaminating $\mathrm{Fc}_{\mathrm{C}}$ receptor lymphocytes in the monocyte monolayers. In preliminary studies, examining the ability of human sera from multiply transfused donors to mediate ADCC, certain sera mediated both monocyte and lymphocyte ADCC, whereas several serum samples appeared to mediate lymphocyte ADCC only. We selected two of these latter sera for further study. In these experiments, CEM targets were sensitized with either of the two human sera or the rabbit anti-CEM serum. The target cells were then added to microwells containing monocyte monolayers, lymphocytes, or no effector cells (spontaneous release) and the ADCC assay performed as usual.

Statistical analysis. Statistical analysis was performed using the Student's $t$ test for nonpaired samples. All values are expressed as mean $\pm 1 \mathrm{SD}$.

\section{RESULTS}

ADCC by monocyte monolayers. Table I illustrates raw ${ }^{51} \mathrm{Cr}$ release data from a typical experiment in which monocytes were examined for their cytotoxic reactivity toward antibody-coated and untreated (control) CEM lymphoblasts. Monocytes and target cells were coincubated at an effector:target cell ratio $(\mathrm{E}: \mathrm{T})$ of $10: 1$ for $4 \mathrm{~h}$. As shown, monocytes produced statistically significant increases in ${ }^{51} \mathrm{Cr}$ release from both antibody coated $(P<0.001)$ and untreated $(P<0.001)$
TABLE I

${ }^{51}$ CR Release from CEM Target Cells* in Presence or Absence of Monocytes

\begin{tabular}{|c|c|c|c|c|}
\hline \multirow{2}{*}{$\begin{array}{l}\text { Monocyte } \\
\text { number }\end{array}$} & \multicolumn{2}{|c|}{ Antibody-coated targets $₫$} & \multicolumn{2}{|c|}{ Untreated targets } \\
\hline & Supernate & ${ }^{51} \mathrm{Cr}$ release & Supernate & ${ }^{31} \mathrm{Cr}$ release \\
\hline & $c p m \S$ & $\%$ & $c p m$ & $\%$ \\
\hline $2 \times 10^{5}$ & $4,658 \pm 336$ & 47.8 & $932 \pm 124$ & 9.6 \\
\hline None & $537 \pm 5$ & 5.5 & $446 \pm 18$ & 4.5 \\
\hline
\end{tabular}

* 20,000 antibody-coated or untreated CEM targets were added to each well $(\mathrm{E}: \mathrm{T}=10: 1)$. These target cells contained $9,737 \pm 350$ total counts per minute.

$\$ 10 \times 10^{6}$ targets were incubated with $0.2 \mathrm{ml}$ of undiluted rabbit immune serum as described in Methods.

$\$$ Expressed as mean $\pm \operatorname{SD}(n=3)$.

lymphoblasts compared to spontaneous release of ${ }^{51} \mathrm{Cr}$ from these target cells incubated alone. Furthermore, monocytes produced much greater ${ }^{51} \mathrm{Cr}$ release from antibody-coated cells compared to untreated, nonantibody-coated CEM lymphocytes $(P<0.001)$. Monocyte ADCC was $38 \%$ in this experiment as calculated by the formula stated in Methods. In general, and for all experiments reported here, an increment in ${ }^{51} \mathrm{Cr}$ release $>3 \%$ represented a statistically significant difference in counts per minute released.

Experiments were then performed using Raji B lymphoblast and HeLa cell targets to demonstrate the expected cross-reactivity of this unabsorbed xenogeneic antiserum as well as the susceptibility of two additional target cell lines to monocyte ADCC. As can be seen in Table II, monocytes produced substantial lysis of all three antibody-coated target cell lines.

The results of these preliminary experiments indi-

TABLE II

${ }^{51} \mathrm{Cr}$ Release from Various Target Cells by Monocyte Monolayers

\begin{tabular}{ccc}
\hline $\begin{array}{c}\text { Target } \\
\text { cell }\end{array}$ & No monocytes & 190,000 monocytes \\
\hline & ${ }^{2{ }^{51} C r \text { release }}$ & $\%{ }^{51}$ Cr release \\
CEM & & \\
T* & $4.6 \pm 0.2 \S$ & $4.5 \pm 0.1$ \\
TAt & $2.9 \pm 0.2$ & $25.9 \pm 3.8$ \\
Raji & $1.7 \pm 0.1$ & $2.1 \pm 0.1$ \\
T & $2.8 \pm 0.3$ & $33.3 \pm 2.0$ \\
TA & $9.2 \pm 1.5$ & $8.2 \pm 0.5$ \\
HeLa & $11.2 \pm 0.8$ & $47.6 \pm 3.9$ \\
T & & \\
TA & & \\
\hline
\end{tabular}

* $\mathrm{T}=19,000$ tumor cells that were not antibody coated. $\$ \mathrm{TA}=19,000$ antibody-coated tumor cells.

$\S$ Expressed as mean $\pm \mathrm{SD}(n=3)$. 
cated to us that the monocyte monolayers were clearly able to carry out ADCC toward tumor cells. To confirm these findings, a series of experiments were performed with the following objectives in mind: $(a)$ to examine the basic characteristics of the cytolytic event; $(b)$ to demonstrate that the cytotoxic process is antibody dependent and requires cell contact; and $(c)$ to establish that the observed cytotoxicity is a result of monocyte activity and not to lymphocyte contamination.

Basic characteristics of monocyte ADCC. The time-course of monocyte-mediated tumor cell lysis was determined by sampling the microtiter wells at $0,2,4$, 10 , and $20 \mathrm{~h}$. Monocyte ADCC was found to be a rapid event with ${ }^{51} \mathrm{Cr}$ release nearing completion by $4 \mathrm{~h}$ (Fig. 1). As shown in Fig. 2, ADCC was positively related to the number of effector cells in the assay (i.e., the effector:target cell ratio). In addition, cytotoxicity was temperature dependent, occurring optimally at $37^{\circ} \mathrm{C}$, moderately well at $23^{\circ} \mathrm{C}$, and not at all at $4^{\circ} \mathrm{C}$ (data not shown). Based on these findings, standard assay conditions were chosen to include a 4-h $37^{\circ} \mathrm{C}$ incubation period and an E:T ratio of 10:1.

Demonstration of the antibody-dependent cellmediated nature of the cytolytic event. Because ADCC depends upon the interaction between target cell-bound antibody and the effector cell $F_{c}$ receptor, cytotoxicity was examined with CEM targets sensitized with various dilutions of immune serum. The results, illustrated in Fig. 3, indicate that ADCC is positively related to the amount of antibody used to sensitize the target cells for both the monocyte and lymphocyte cell preparations. Monomeric immunoglobulin has been employed to selectively disrupt the $F_{c}$ receptormediated interaction between effector cells and anti-

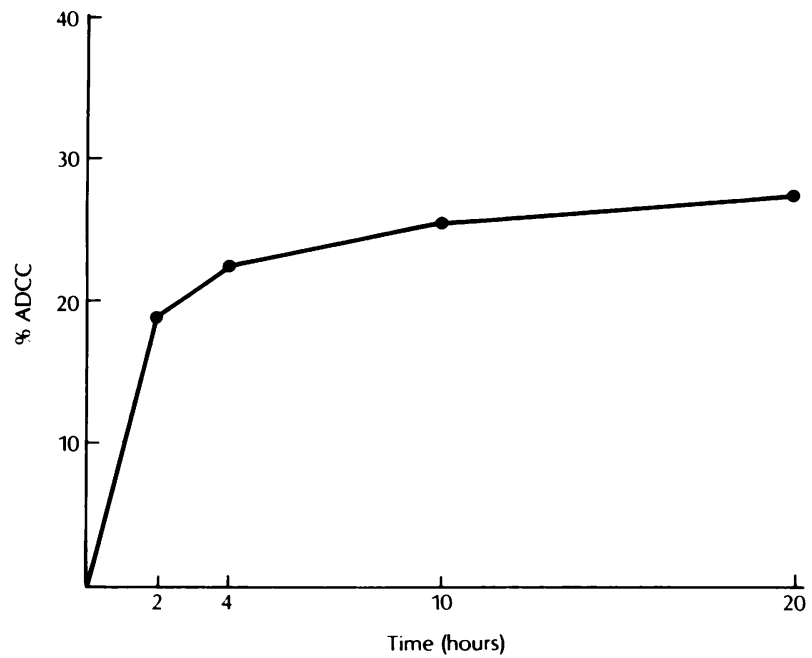

Figure 1 Time-course of monocyte ADCC. Antibody- and control nonantibody-coated CEM target cells were added to microwells containing 300,000 suspension monocytes. E:T $=10: 1$.

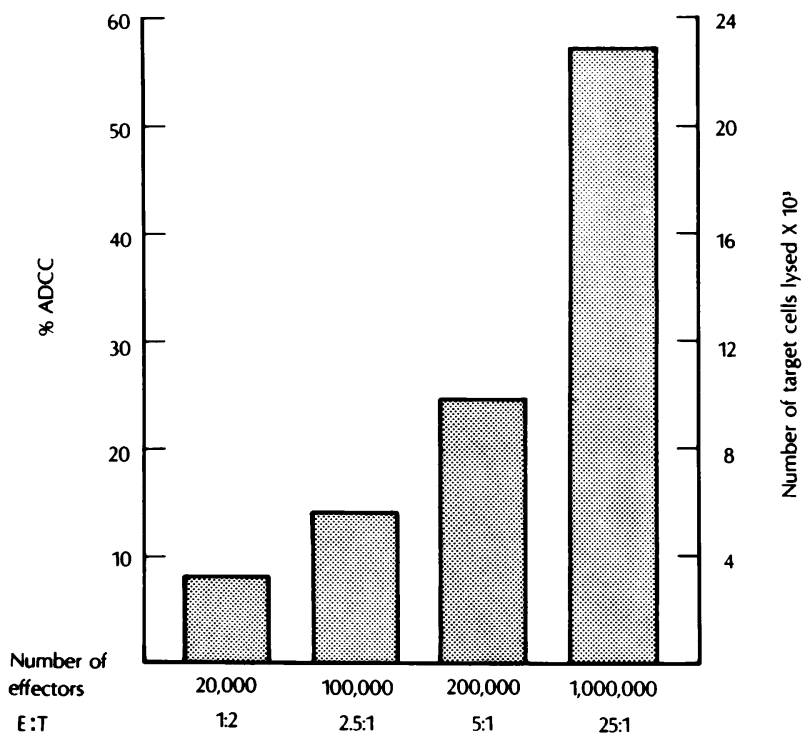

Figure 2 Effects of E:T ratio on monocyte ADCC. CEM targets $(40,000)$ were added to microwells containing varying numbers of suspension monocytes. Data are expressed in terms of the percentage of ADCC and number of target cells lysed.

body-coated target cells (31). In our assay, monomeric immunoglobulin produced a dose-related inhibition of monocyte ADCC (Fig. 4).

Evidence that the cytotoxic event was mediated by

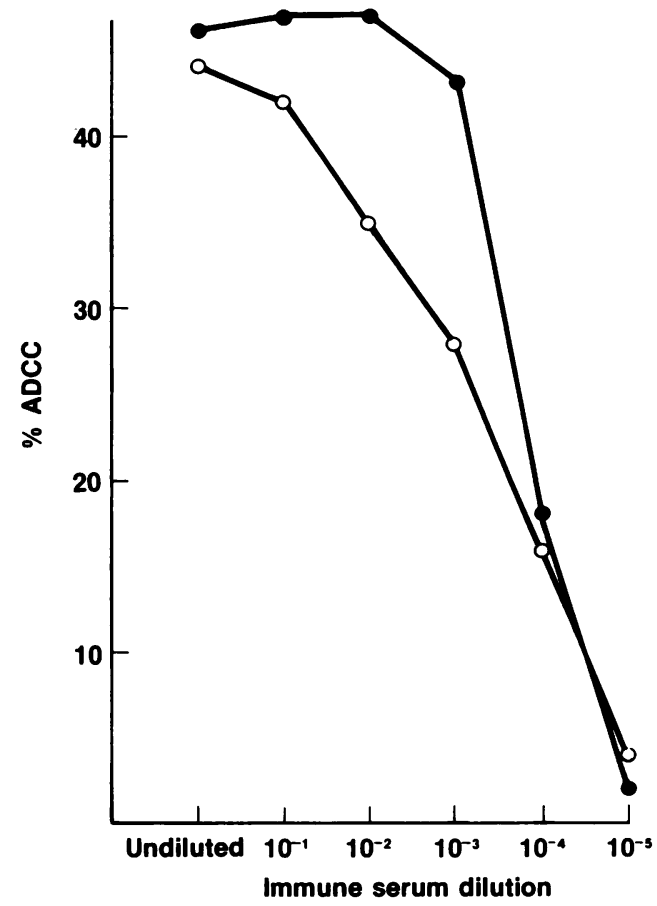

FIGURE 3 Effects of immune rabbit serum dilution on monocyte $(O)$ and lymphocyte $(O)$ ADCC. $10 \times 10^{6} \mathrm{CEM}$ targets were sensitized with $0.2 \mathrm{ml}$ of each serum dilution. $\mathrm{E}: \mathrm{T}=10: 1$. 


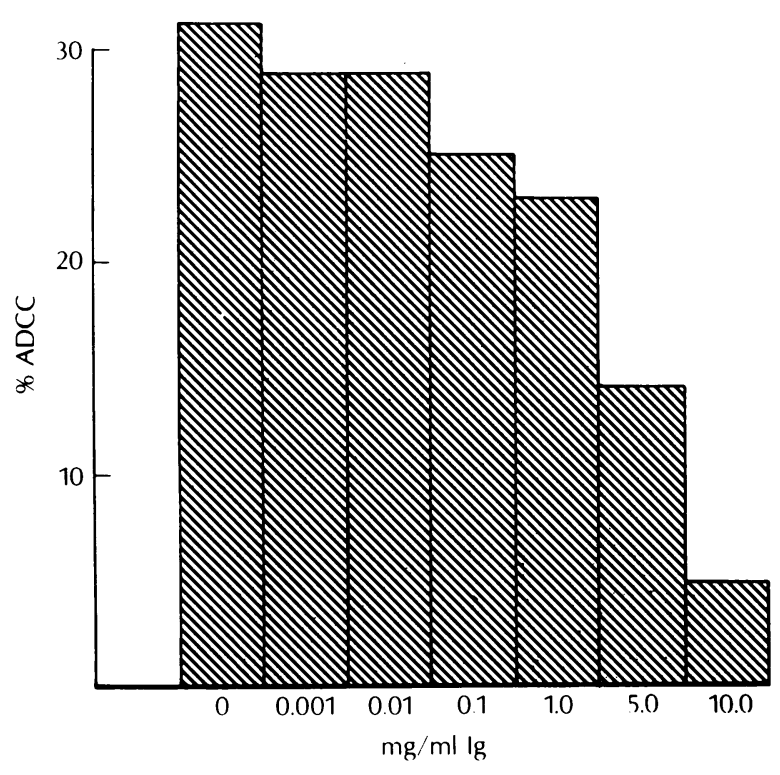

FIGURE 4 Inhibition of monocyte ADCC by nonspecific immunoglobulin. Monocyte monolayers were preincubated at $37^{\circ} \mathrm{C}$ for $30 \mathrm{~min}$ with various concentrations of monomeric nonspecific immunoglobulin. Antibody- and control nonantibody-coated targets were then added directly to the immunoglobulin-containing microwells and the assay carried out as previously described. $\mathrm{E}: \mathrm{T}=10: 1$.

the $\mathrm{Fc}$ region of IgG was obtained by studies examining the effect of incubation of antibody-coated CEM targets with SPA before incubation with monocytes. SPA is known to bind to the $\mathrm{Fc}_{\mathrm{c}}$ region of IgG and interfere with lymphocyte ADCC (32). CEM target cells sensitized with $10^{-2}$ and $10^{-3}$ dilutions of rabbit antiCEM were incubated with or without $100 \mu \mathrm{g}$ of SPA before incubation with monocyte preparations. The SPA produced 75-100\% inhibition of ADCC depending upon the degree of antibody sensitization. Finally, additional evidence that the cytotoxic event is antibody dependent and cell contact mediated was obtained by an innocent bystander study. In the experiment illustrated in Table III, suspension monocytes were reacted with antibody- or nonantibody-coated CEM targets, each bearing the ${ }^{51} \mathrm{Cr}$ label. In other wells, monocytes were reacted with mixtures of antibody- and nonantibody-coated targets, only one of which was ${ }^{51} \mathrm{Cr}$ labeled. As shown in Table III, monocytes produced substantial lysis of antibodycoated CEM targets whether or not nonantibodycoated targets were included in the same wells. On the other hand, ${ }^{51} \mathrm{Cr}$-labeled nonantibody-coated targets were not lysed by monocytes despite being present in the same cell button where antibodycoated cells were being actively destroyed. The experiment was carried out with a $10^{-3}$ dilution of antisera to decrease the likelihood of antibody transfer to the
TABLE III

Innocent Bystander Study

\begin{tabular}{|c|c|c|}
\hline Target cells* & No monocytes & 100,000 monecytes \\
\hline & $\%{ }^{51} \mathrm{Cr}$ release & $\%{ }^{51} \mathrm{Cr}$ release \\
\hline TA & $2.7 \pm 0.3 \oint$ & $22.0 \pm 0.6$ \\
\hline $\mathrm{T} \ddagger$ & $4.1 \pm 0.2$ & $6.2 \pm 0.5$ \\
\hline $\mathrm{TA}$ and $\mathrm{T} \ddagger$ & $3.0 \pm 0.2$ & $6.2 \pm 0.4$ \\
\hline TAt and $T$ & $3.4 \pm 0.2$ & $21.8 \pm 2.2$ \\
\hline
\end{tabular}

* TA refers to 10,000 antibody-coated CEM targets. Target cells $\left(10 \times 10^{6}\right)$ were sensitized with $0.2 \mathrm{ml}$ of a $10^{-3}$ dilution of immune rabbit serum. $T$ refers to 10,000 nonantibodycoated CEM lymphoblasts.

$\$$ Refers to the target cell population that was ${ }^{51} \mathrm{Cr}$ labeled. $\S$ Expressed as mean $\pm \operatorname{SD}(n=3)$.

nonantibody-coated cells which does occur with heavily sensitized target cells (personal observation). These data furthermore present evidence against a soluble mediator of the cytolytic event.

Evidence that ADCC results from monocyte and not contaminating lymphocyte activity. The purity of all monocyte preparations was $>95 \%$ based on nonspecific esterase staining, morphologic characteristics of supravital, and Wright's-Giemsa stained preparations, and the ability of these cells to ingest latex particles. Moreover, the cytotoxic activity of these purified monocyte preparations was equivalent to that of purified lymphocytes. In 12 experiments, monocytes and lymphocytes isolated from the same donors produced $28 \pm 13$ and $34 \pm 17 \%$ ADCC, respectively $(P>0.2)$.

The effect of preincubation of effector cells with zymosan particles is illustrated in Fig. 5. Zymosan ingestion leads to selective inhibition of monocyte ADCC with virtually no effect on lymphocyte ADCC. To be sure that monocytes ingesting zymosan do not adversely effect lymphocyte ADCC, the same experiment was carried out with a third effector cell population made up by mixing equal numbers of monocytes and lymphocytes together. In this experiment, zymosan inhibition of ADCC was $85 \%$ for monocytes, $10 \%$ for lymphocytes, and $41 \%$ for the equal mixture of monocytes and lymphocytes. The two effector cell preparations were further distinguished by their activity toward different antibody-coated target preparations. In Fig. 6, monocytes and lymphocytes were reacted with CEM lymphoblast targets presensitized with either rabbit anti-CEM serum or one of two sera from multiply transfused human donors. As shown, the antibodies from these human sera were able to mediate ADCC by the lymphocyte preparation but not by the monocyte monolayers. These identical monocyte monolayers, however, were able to produce striking ADCC to rabbit antibody-coated targets. These data 


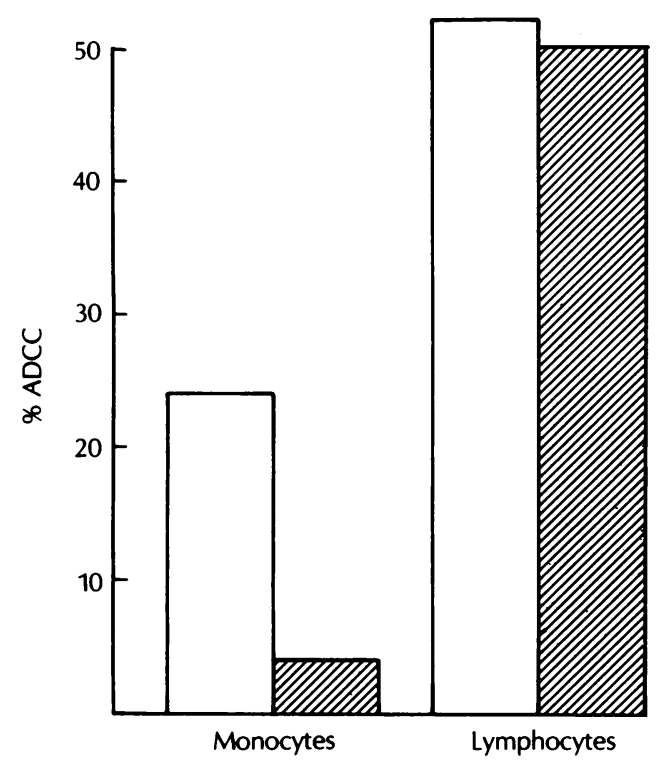

FIGURE 5 Differential inhibition of monocyte and lymphocyte ADCC by opsonized zymosan particles. Monocytes and lymphocytes were preincubated at $37^{\circ} \mathrm{C}$ with opsonized zymosan for $1 \mathrm{~h}$ before the addition of CEM target cells. Cross-hatched bars refer to ADCC by monocytes and lymphocytes pretreated with opsonized zymosan. Open bars refer to control ADCC by these same effector cells preincubated without zymosan. $\mathrm{E}: \mathrm{T}=10: 1$.

demonstrate the lack of significant $\mathrm{Fc}_{\mathrm{c}}$ receptor $\mathrm{K}$ lymphocyte contamination of the monocyte monolayer preparations. The data further emphasize the observation that different antisera are capable of selectively mediating ADCC by different effector cells (11, $17,36,37)$.

\section{DISCUSSION}

Previous studies of mononuclear cell ADCC toward lymphoid or tumor cell targets indicate that $\mathrm{Fc}$ receptor bearing lymphocytes and not monocytes are able to lyse these target cells $(1-3,11-14,16-18)$. The results of this investigation, however, demonstrate that purified monolayer or suspension preparations of human monocytes are able to carry out ADCC to several tumor cell lines. This cytotoxic activity was clearly antibody dependent in that it was directly related to the degree of antibody sensitization of the target cell, was inhibited by soluble immunoglobulin, and did not injure innocent bystander target cells that were not antibody coated.

Because purified cell preparations derived from blood are never $100 \%$ pure, we developed considerable evidence that the observed cytotoxicity was a monocyte dependent event. The major concern was that the monocyte preparations might be contaminated with $\mathrm{Fc}_{\mathrm{c}}$ receptor-bearing lymphoid cells which are capable of

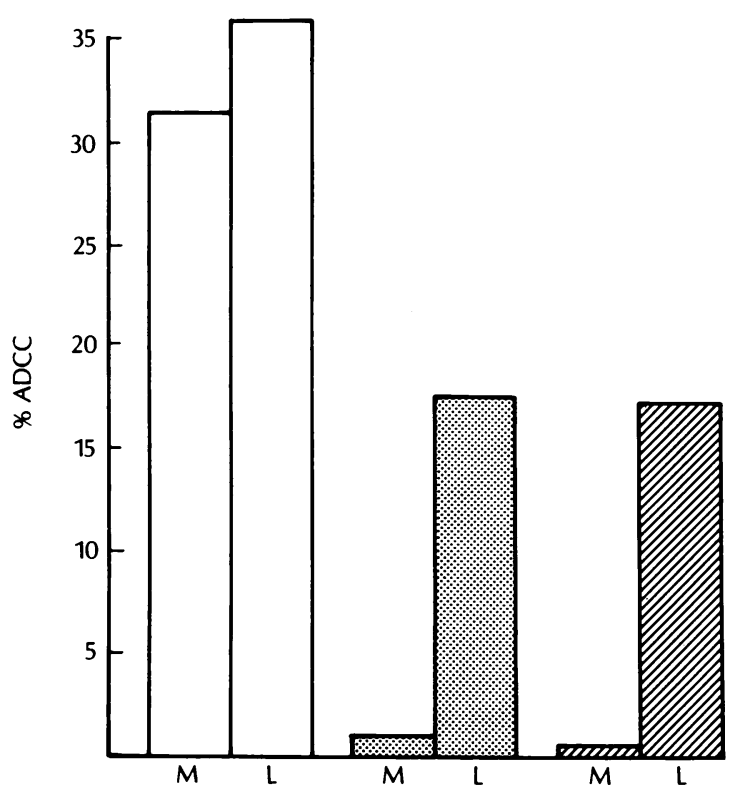

Figure 6 . Monocyte (M) and lymphocyte (L) cytotoxicity toward CEM target cells coated with different antibodies. CEM targets were sensitized with immune rabbit serum (open bars) and serum from multiply-transfused donor J.A. (stippled bars) and E.L. (cross-hatched bars). E:T = 10:1.

mediating ADCC to tumor cells. Several observations make this possibility untenable. First, Fc receptor lymphocytes have been characterized as "nonadherent" under the conditions used to prepare the monocyte monolayers (25). We have confirmed this fact by demonstrating that lymphocyte preparations depleted of monocytes by iron ingestion (Methods) are unable to form monolayers of cells capable of ADCC in our assay system. Further, the attempt at forming monolayers does not reduce lymphocyte ADCC activity of the nonadherent cells (unpublished observations). Second, comparable degrees of cytotoxicity were seen with monocyte preparations ( $<5 \%$ lymphocytes) as compared to lymphocyte preparations ( $>95 \%$ lymphocytes) at identical 10:1 E:T cell ratios. Furthermore, zymosan preincubation abolished cytotoxicity by monocyte preparations without affecting cytotoxicity by the lymphocyte preparations (Fig. 5). Finally, no lymphoid ADCC activity was found in the monocyte preparations using antibody coated-target cells that were selectively lysed by lymphocytes (Fig. 6).

The reason(s) why other investigators have failed to observe monocyte ADCC are not clear, but several factors may be important. First, the particular antibody, target cell combination appears to be of primary importance. For example, Clark and Klebanoff (37) have reported antisera and culture conditions that allow ADCC to tumor cells by human neutrophils but not by 
lymphocytes or monocytes. Similarly, two antibodycoated targets were lysed in our assay by lymphocytes but not by monocytes, whereas rabbit antibodycoated targets were lysed by both effector cell preparations (Fig. 6). It is of interest, though, that in preliminary studies, we have found antibodies in sera from multiply transfused patients that do mediate both lymphocyte and monocyte ADCC (36). Furthermore, studies examining ADCC to human erythrocyte targets have shown that cytotoxicity results from monocyte but not lymphocyte activity $(22,38)$. However, we have recently demonstrated that striking lymphocyte ADCC can occur with human erythrocyte targets and that this cytotoxic event is dramatically dependent on the distribution and(or) density of the target-bound antibody (39). Thus, prior studies that use assay conditions optimal for lymphocyte ADCC to tumor cells may not have had assay conditions suitable for monocyte interaction with target cell. The fact that a number of investigations $(11,13,40,41)$ used an identical target combination (Chang cells and highly diluted rabbit anti-Chang serum) makes this possibility even more real.

Another factor possibly related to the failure of other studies to document monocyte ADCC involves the methods used to examine monocytes for cytotoxic activity. Several reports $(13,14,18,42)$ suggested that monocytes do not carry out ADCC based on data from monocyte depletion experiments. In these studies, which compare ADCC by equal numbers of whole mononuclear cells and monocyte depleted mononuclear cell preparations, it was concluded that monocytes were not active since ADCC did not fall after their selective removal. These data, however, should be interpreted to indicate only that the remaining lymphocytes in the monocyte depleted preparations possess ADCC activity. No inferences can be made regarding the cytotoxic potential of the removed monocytes. Indeed, when we repeated such experiments using rabbit antibody-coated CEM lymphoblast targets, ADCC actually increased slightly after monocyte depletion. Yet, as shown in this report, monocytes isolated from these mononuclear preparations are capable of substantial ADCC.

Thus, it seems that few studies have examined a wide range of antibody target combinations with experiments specifically designed to demonstrate monocyte ADCC. There has, however, been a recent report by Kohl et al. (9) in regard to monocyte-macrophage ADCC to herpes-infected Chang cells coated with antiviral antibody. They suggest that monocytes can produce ${ }^{51} \mathrm{Cr}$ release from nucleated target cells, but their data differ in several respects from the observations in this study. The most dramatic difference is in the kinetics of the cytotoxic activity. Kohl et al. (9) found no cytotoxicity in the first $6-8 \mathrm{~h}$ of cell interaction and determined an incubation of 18-24 $\mathrm{h}$ to be optimal.
Those findings are at odds with most reported data describing the kinetics of ADCC reactions $(3,15,37,43)$ including monocyte ADCC to human erythrocytes (22). In our system, the antibody-dependent aspect of monocyte cytotoxicity occurred, for the most part, in the first $4 \mathrm{~h}$ of incubation with little increase in ${ }^{51} \mathrm{Cr}$ release thereafter (Fig. 1). Another difference between the report by Kohl et al. (9) and this work involves the extent of target cell lysis. Their study used an E:T ratio of 30:1 that resulted in lysis of 1,200-1,500 target cells over an $18 \mathrm{~h}$ period. In our assay, performed at an $E: T$ ratio of 10:1, the number of target cells lysed on generally in the range of 3,000-6,000 cells over $4 \mathrm{~h}$ and was as large as 23,000 target cells lysed when the assay was carried out at an E:T ratio of 25:1 (Fig. 2). Thus, the monocyte cytotoxicity described in this report seems quite different from that described by Kohl et al. (9).

The biochemical mechanism that results in target cell lysis in ADCC is unclear but the report of Clark and Klebanoff (37) that neutrophil ADCC is dependent on oxidative metabolism and is impaired in effector cells derived from patients with chronic granulomatous disease suggests that the mechanisms might be similar to those operative in the bactericidal event. Monocyte ADCC shares similarities with that of lymphocytes and neutropholis. The cytotoxic event is rapid, temperature dependent, and requires intimate effectortarget contact mediated through the $\mathrm{Fc}_{\mathrm{c}}$ receptor. In addition, the innocent bystander study provides evidence against a soluble mediator of target cell lysis, i.e., lymphotoxin or similar stable cell lysin (44). However, this would not exclude a soluble factor which selectively damages antibody-coated cells or oxygen radicals or other unstable factors with very brief survival times which may only be capable of target cell membrane damage at interfaces of intimate effectortarget membrane interaction. Further studies will be needed to characterize the mechanisms involved in this cytotoxic event.

The fact that monocytes can carry out ADCC may be important for several reasons. Prior studies in animal models indicate that tissue macrophages may carry out ADCC to tumor cells in vivo (6-8). The failure to demonstrate ADCC by blood monocytes in vitro suggested that these circulating precursors of tissue macrophages require further cell differentiation (in tissues) before developing this cytotoxic potential. A recent report by Mantovani et al. (45), in fact, reports that human blood monocytes are incapable of ADCC but develop this activity after 5-10 days of in vitro culture. This study shares many of the deficiencies previously discussed. In particular, the assay conditions selected to test monocyte ADCC were those that were best for lymphocyte ADCC in their system. Moreover, the cytotoxicity by their in vitro differentiated 
macrophages was minimal at best, amounting to $9.4 \%$ ADCC over a 24 -h incubation with no cytolysis over 4-6-h periods of incubation. In contrast to this report and others, our data clearly demonstrate that monocytes isolated from normal individuals and assayed 3-4 h post-phlebotomy can carry out prompt and striking degrees of ADCC.

There is a growing awareness that the monocytemacrophage system may play an important role in cellmediated resistance to viral infection (9) and possibly neoplasia (6-8). Eccles and Alexander (46) have reported an inverse relationship between macrophage content of tumors and their propensity to metastasis in certain animal models. In human breast cancer, macrophage infiltration of tumor draining nodes appears to be a good prognostic factor (47). Furthermore, Haskill (8, $48)$ and Yamamura (49) have recently reported studies in a murine breast tumor model which indicate that macrophage response to tumors may be operative in tumor regression and that these cells are producing their antitumor effect by an ADCC mechanism. We would suggest that blood monocytes arriving at sites of inflammation or sites of tumor proliferation are capable of carrying out ADCC without further differentiation. The techniques used in this work are applicable to the study of this potentially important cell function in patients with various diseases or those undergoing immunologic or other forms of therapeutic manipulation. Finally, use of this assay may allow characterization of the basic mechanisms involved in monocyte destruction of antibody-coated target cells.

\section{ACKNOWLEDGMENTS}

We wish to thank Helen Ilc for her help in manuscript preparation and Joe Dalmasso for his technical assistance.

This investigation was supported by grants from the National Cancer Institute NO2-CB-53936 and the American Cancer Society IM-109.

\section{REFERENCES}

1. MacLennan, I. C. M. 1976. Function and evaluation of human K-cells. In Clinical Tumor Immunology. J. Wybran and M. J. Staquet, editors. Pergamon Press Ltd., Oxford, England. 47-53.

2. Perlmann, P. 1976. Cellular immunity: antibody-dependent cytotoxicity (K-cell activity). In Clinical Immunobiology. F. H. Bach and R. A. Good, editors. Academic Press, Inc., New York. 3: 107-132.

3. Henney, C. S. 1977. Mechanisms of tumor cell destruction. In Mechanisms of Tumor Immunity. S. Cohen and R. T. McCluskey, editors. John Wiley \& Sons, Inc., New York. 55-86.

4. Ting, A., and P. I. Terasaki. 1974. Influence of lymphocyte-dependent antibodies on human kidney transplants. Transplantation (Baltimore). 18: 371-373.

5. Pollack, S., G. Heppner, R. J. Brawn, and K. Nelson. 1972. Specific killing of tumor cells in vitro in the presence of normal lymphoid cells and sera from hosts immune to the tumor antigens. Int. J. Cancer. 9: 316-323.
6. Shin, H., N. Kaliss, D. Borenstein, and M. Gately. 1972. Antibody mediated suppression of grafted lymphoma cells. II. Participation of macrophages. J. Exp. Med. 136: 375-380.

7. Johnson, R., G. Pasternak, and H. Shin. 1977. Antibodymediated suppression of tumor growth. J. Immunol. 118: 494-497.

8. Haskill, J., and J. Felt. 1976. Possible evidence for antibody dependent macrophage cytotoxicity against murine adenocarcinoma cells in vivo. J. Immunol. 117: 19921998.

9. Kohl, S. S. E. Starr, J. M. Oleske, S. L. Shore, R. B. Ashman, and A. J. Nahmias. 1977. Human monocytemacrophage-mediated antibody-dependent cytotoxicity to Herpes simplex virus-infected cells. J. Immunol. 118: 729-735.

10. Calder, E. A., W. J. Penhale, D. McLeman, E. W. Barnes, and W. J. Irvine. 1973. Lymphocyte-dependent antibodymediated cytotoxicity in Hashimoto's thyroiditis. Clin. Exp. Immunol. 14: 153-158.

11. Nelson, D. L., B. M. Bundy, H. E. Pitchon, R. M. Blaese, and W. Strober. 1976. The effector cells in human peripheral blood mediating mitogen-induced cellular cytotoxicity and antibody-dependent cellular cytotoxicity. J. Immunol. 117: 1472-1480.

12. Trinchieri, G., P. Bauman, M. Marchi, and Z. Tökes. 1975. Antibody-dependent cell-mediated cytotoxicity in humans. I. Characterization of the effector cell. J. Immunol. 115: 249-255.

13. Kay, H. D., G. D. Bonnard, W. W. West, and R. B. Herberman. 1977. A functional comparison of human Fcreceptor-bearing lymphocytes active in natural cytotoxicity and antibody-dependent cellular cytotoxicity. J. Immunol. 118: 2058-2066.

14. Melewicz, F. M., S. L. shore, E. W. Ades, and D. J. Phillips. 1977. The mononuclear cell in human blood which mediates antibody-dependent cellular cytotoxicity to virus-infected cells. II. Identification as a $K$ cell. $J$. Immunol. 118: 567-573.

15. Gale, R. P., and J. Zighelboim. 1975. Polymorphonuclear leukocytes in antibody-dependent cellular cytotoxicity. J. Immunol. 114: 1047-1051.

16. Yust, I., J. R. Wunderlich, D. L. Mann, and W. D. Terry. 1974. Identification of lymphocyte-dependent antibody in sera from multiply transfused patients. Transplantation (Baltimore). 118: 99-107.

17. Yust, I., J. R. Wunderlich, D. L. Mann, and D. N. Buell. 1973. Cytotoxicity mediated by human lymphocyte-dependent antibody in a rapid assay with adherent target cells. J. Immunol. 110: 1672-1681.

18. Shore, S. L., F. M. Melewicz, and D. S. Gordon. 1977. The mononuclear cell in human blood which mediates antibody-dependent cellular cytotoxicity to virus-infected target cells. I. Identification of the population of effector cells. J. Immunol. 118: 558-566.

19. LoBuglio, A. F., R. S. Cotran, and J. H. Jandl. 1967. Red cells coated with immunoglobulin G: Binding and sphering by mononuclear cells in man. Science (Wash. D. C.). 158: $1582-1584$.

20. Abramson, N., A. F. LoBuglio, J. Jandl, and R. Cotran. 1970. The interaction between human monocytes and red cells. Binding characteristics. J. Exp. Med. 132: 11911206.

21. Meier, C. R., H. Laufman, and A. F. LoBuglio. 1977. Characterization of human monocyte antibody dependent cellular cytotoxicity (ADCC) to red cells. Clin. Res. 25(A): 579A. (Abstr.)

22. Kurlander, R. J., W. F. Rosse, and G. L. Logue. 1978. 
Quantitative influence of antibody and complement coating of red cells on monocyte-mediated cell lysis. $J$. Clin. Invest. 61: 1309-1319.

23. Bøyum, A. 1976. Isolation of lymphocytes, granulocytes and macrophages. Scand. J. Immunol. 5(Suppl. 5): 9-15.

24. Koller, C. A., G. W. King, P. E. Hurtubise, A. L. Sagone, and A. F. LoBuglio. 1973. Characterization of glass adherent human mononuclear cells. J. Immunol. 111: 1610-1612.

25. Horwicz, D. A., and M. A. Garrett. 1977. Distinctive functional properties of human blood L lymphocytes: a comparison with $\mathrm{T}$ lymphocytes, B lymphocytes, and monocytes. J. Immunol. 118: 1712-1721.

26. Frøland, S. S., and F. Wisl $\phi f f . ~ 1976$. A rosette technique for identification of human lymphocytes with Fc receptors. In In Vitro Methods in Cell-Mediated and Tumor Immunity. B. R. Bloom and J. R. David, editors. Academic Press, Inc., New York. 137-142.

27. Foley, G. E., H. Lazarus, S. Farber, B. G. Usman, B. A. Boone, and R. E. McCarthy. 1965. Continuous culture of human lymphoblasts from peripheral blood of a child with acute leukemia. Cancer. 18: 522-529.

28. Kaplan, J., T. C. Shope, and W. D. Peterson, Jr. 1974. Epstein-Barr virus-negative human malignant T-cell lines. J. Exp. Med. 139: 1070-1076.

29. Romano, P. J., and D. L. Mann. 1976. Specific MLC stimulation by cultured B cells. Tissue Antigens. 8: 9-12.

30. Brunner, K. T., H. D. Engers, and J. C. Cerottini. 1976. The ${ }^{51} \mathrm{Cr}$ release assay as used for the quantitative measurement of cell-mediated cytolysis in vitro. In Mechanisms of Cell Mediated Immunity. B. R. Bloom and J. R. David, editors. Academic Press, Inc., New York. 423-428.

31. Ziegler, H. K., and C. S. Henney. 1977. Studies on the cytotoxic activity of human lymphocytes. II. Interactions between IgG and $\mathrm{Fc}$ receptors leading to inhibition of $\mathrm{K}$ cell function. J. Immunol. 119: 1010-1017.

32. Rosenblatt, J., Zeltzer, P., Portaro, J. and Seeger, R. 1977. Inhibition of antibody-dependent cellular cytotoxicity by Protein A from Staphylococcus Aureus. J. Immunol. 118: 981-985.

33. Gewurz, H., and T. F. Lint. 1977. Alternative modes and pathways of complement activation. In Biological Amplification Systems in Immunology. N. K. Day and R. A. Good, editors. Plenum Medical Book Co., New York. 1745.

34. Weiss, S. J., G. W. King, and A. F. LoBuglio. 1978. Superoxide generation by human monocytes and macrophages. Am. J. Hematol. 4: 1-8.

35. Bankhurst, A. D., E. Hastain, G. Husby, E. DizaJouanen, and R. C. Williams, Jr. 1978. Human lympho- cyte subpopulations defined by double surface markers. J. Lab. Clin. Med. 91: 15-23.

36. Shaw, G. M., P. C. Levy, and A. F. Lobuglio. 1977. Human monocyte antibody dependent cellular cytotoxicity (ADCC). Blood. 50: 177. (Abstr.)

37. Clark, R. A., and S. J. Klebanoff. 1977. Studies on the mechanism of antibody-dependent polymorphonuclear leukocyte-mediated cytotoxicity. J. Immunol. 119(4): 1413-1418.

38. Poplack, D. G., G. D. Bonnard, B. J. Holiman, and M. Blaese. 1976. Monocyte-mediated antibody dependent cellular cytotoxicity: clinical test of monocyte function. Blood. 48: 809-816.

39. Shaw, G. M., P. C. Levy, and A. F. LoBuglio. 1978. Human lymphocyte antibody-dependent cell-mediated cytotoxicity toward human erythrocytes. Blood. 52: 696705.

40. Nelson, D. L., B. M. Bundy, and W. Strober. 1977. Spontaneous cell-mediated cytotoxicity by human peripheral blood lymphocytes in vitro. J. Immunol. 119: 1401-1405.

41. Ortaldo, J. R., G. D. Bonnard, and R. B. Herberman. 1977. Cytotoxic reactivity of human lymphocytes cultured in vitro. J. Immunol. 119: 1.351-1357.

42. Sanal, O., and R. H. Buckley. 1978. Antibody-dependent cellular cytotoxicity in primary immunodeficiency diseases and with normal leukocyte subpopulations. J. Clin. Invest. 61: 1-10.

43. Romano, T. J., and S. L. Shore. 1977. Lysis of virusinfected target cells by antibody-dependent cellular cytotoxicity. Cell Immunol. 30: 66-81.

44. Yoshida, T., and S. Cohen. 1977. Lymphokines in tumor immunity. In Mechanisms of Tumor Immunity. I. Green, S. Cohen, and R. T. McCluskey, editors. John Wiley \& Sons, Inc., New York. 87-108.

45. Mantovani, A., V. Caprioli, P. Gritti, and F. Spreafico. 1977. Human mature macrophages mediate antibody dependent cellular cytotoxicity on tumor cells. Transplantation (Baltimore). 24: 291-293.

46. Eccles, S. A., and P. Alexander. 1974. Macrophage content of tumors in relation to metastatic spread and host immune reaction. Nature (Lond.). 250: 667-669.

47. Silverberg, S. G., A. R. Chitale, A. D. Hind. A. R. Frazier, and S. H. Levit. 1970. Sinus histiocytosis and mammary carcinoma. Cancer. 26: 1177-1185.

48. Haskill, J. S. 1977. ADCC effector cells in a murine adenocarcinoma. I. Evidence for blood-borne bone-marrow-derived monocytes. Int. J. Cancer. 20: 432-440.

49. Yamamura, Y. 1977. Immunologic responses to a murine mammary adenocarcinoma. II. Monocyte effector activation by humoral factors. Int. J. Cancer. 19: 717-724. 